\title{
Using Landsat satellite data for assessing the land use and land cover change in Kashmir valley
}

\author{
Akhtar Alam (D) - M. Sultan Bhat • M. Maheen
}

Published online: 22 June 2019

(C) The Author(s) 2019

\begin{abstract}
Land use and land cover (LULC) change has been one of the most immense and perceptible transformations of the earth's surface. Evaluating LULC change at varied spatial scales is imperative in wide range of perspectives such as environmental conservation, resource management, land use planning, and sustainable development. This work aims to examine the land use and land cover changes in the Kashmir valley between the time periods from 1992-2001-2015 using a set of compatible moderate resolution Landsat satellite imageries. Supervised approach with maximum likelihood classifier was adopted for the classification and generation of LULC maps for the selected time periods. Results reveal that there have been substantial changes in the land use and cover during the chosen time periods. In general, three land use and land cover change patterns were observed in the study area: (1) consistent increase of the area under marshy, built-up, barren, plantation, and shrubs; (2) continuous decrease in agriculture and water; (3) decrease (1992-2001) and increase (2001-2015) in forest and pasture classes. In terms of the area under each LULC category, most significant changes have
\end{abstract}

\footnotetext{
A. Alam $(\bowtie)$

Institute for Risk and Disaster Reduction, University

College London, London WC1E 6BT, UK

e-mail: akhtar.alam@ucl.ac.uk
}

\author{
A. Alam - M. S. Bhat - M. Maheen \\ Department of Geography and Regional Development, \\ University of Kashmir, Srinagar 190006, India
}

been observed in agriculture $(-)$, plantation $(+)$, builtup $(+)$, and water (-); however, with reference to percent change within each class, the maximum variability was recorded in built-up (198.45\%), plantation $(87.98 \%)$, pasture $(-71 \%)$, water $(-48 \%)$ and agriculture $(-28.85 \%)$. The massive land transformation is largely driven by anthropogenic actions and has been mostly adverse in nature, giving rise to multiple environmental issues in the ecologically sensitive Kashmir valley.

Keywords Land use and land cover - Change detection $\cdot$ Landsat data $\cdot$ Classification $\cdot$ Kashmir valley

\section{Introduction}

Land use and land cover (LULC) are two transposable terms; however, used with different connotations in land change science. Land use refers to 'human activities on and in relation to the land, which are usually not directly visible from the imagery' (Lo 1986), while as land cover describes, 'the vegetation and artificial constructions covering the land surface' (Burley 1961). Land use and land cover matrix is intrinsic element of the landscape, having direct and indirect links with varied geophysical and socioeconomic processes. The rate and spatial scale of human 
alterations to land surface mostly in the form of land use and land cover change are unprecedented and so invasive that they enormously transformed a large proportion of the planet's land surface, affecting key aspects of earth systems (Lambin et al. 2001; Foley et al. 2005). The controlling factor of rapidness and pattern in LULC change by humans mainly depends on their social, economic, and political characteristics (Ojima et al. 1994).

Land use and land cover change assessment has become central to diverse facets of human and natural environment, and interplay between the two (Foody 2002; Herold et al. 2002; Ji et al. 2005; Diallo et al. 2009; Hegazy and Kaloop 2015; Liu and Yang 2015). Evaluating land use and land cover is imperative to overcome a series of environmental issues at regional level such as unregulated development, loss of agricultural lands, destruction of wetlands, and wildlife habitat (Anderson et al. 1976). Moreover, the LULC changes deserve more consideration in land management owing to their usually impending negative impact on status and integrity of ecosystem functioning (Quintas-Soriano et al. 2016). With increasing pressure on land resources owing to population growth and expansion of human settlement, LULC is also of great relevance to policies on Disaster Risk Reduction (DRR) and climate change adaptation (e.g., David et al. 2016; Shaw and Banba 2017).

Land use and land cover change studies attempt to explain (1) where change is occurring, (2) what land cover types are changing, (3) the types of transformation occurring, (4) the rates or amounts of land change, and (5) the driving forces and proximate causes of change (Loveland and Acevedo 2006). What would be the future change patterns of the land use and land cover, mostly derived through simulation modelling is also an imperative dimension of such investigations. In order to understand when, where, and why LULC changes occur, the models usually involve empirically fitting the evaluation system to some historical pattern of change, then extending those patterns into the future for projection (Brown et al. 2000).

All these aspects of the land use and land cover change are measured reliably through the use of remote sensing satellite data. Remote sensing is currently most reliable tool for monitoring varied spectrally sensitive changes of the earth. The information obtained through the technology is also crucial for modelling other natural and cultural processes
(Jensen 2007). Remote sensing imageries with variable resolutions in combination with the use of different descriptive models, offer an extraordinary prospect to obtain past, present and future land use and land cover patterns (for details see Lambin 1997; Li et al. 2014). Over years LULC change assessment has been effectively performed through the use of satellite data in cost and time effective manner (Barnsley and Barr 1996; Yang 2002; Yang and Liu 2005; Güler et al. 2007; Erener et al. 2012; Shah 2012). From the operational point of view, monitoring LULC changes has been most adopted and common application of the satellite data (Nelson 1983; Singh 1989; Turner et al. 1993; Seto and Kaufmann 2005).

Among various earth observation (EO) programmes NASA's Landsat missions are known for free dissemination of extensive data. With longest (since 1972) continual global coverage at moderate to high resolution, the Landsat data has been commonly used for LULC change detection (e.g., Helmer et al. 2000; Lu and Weng 2004; Gao and Zhang 2009; Gumma et al. 2011; Lu et al. 2012; Jia et al. 2014; Kumar and Acharya 2016).

Kashmir valley witnessed drastic land use and land cover changes mainly as a result of increase in population size, economic growth, changes in agriculture practices, and execution of different development projects particularly during last three decades. However, the LULC changes are not being monitored in a systematic way and estimation of the magnitude of the changes is rarely being done; hence, knowledge of the LULC dynamics in the region is scarce. In the present study we attempt to map and quantify the LULC changes in NW-SE oriented central segment of the Kashmir valley (Fig. 1) during last three decades (1992-2001-2015), using multi-temporal remote sensing satellite data.

\section{Study area}

Kashmir valley is a NW-SE oriented elongated trough located in northwest Himalaya (Fig. 1), owing its origin to extensional tectonic movement along a local basement fault (Alam et al. 2015a, b, 2017; Ahmad et al. 2015). The actual area of interest for this study forms the considerable central part $(\sim 16 \%)$ of the valley, spread over an area of $\sim 2400 \mathrm{~km}^{2}$ between 
Fig. 1 Location of the study area (SRTM DEM); a Kashmir Valley (shaded), b actual area of interest
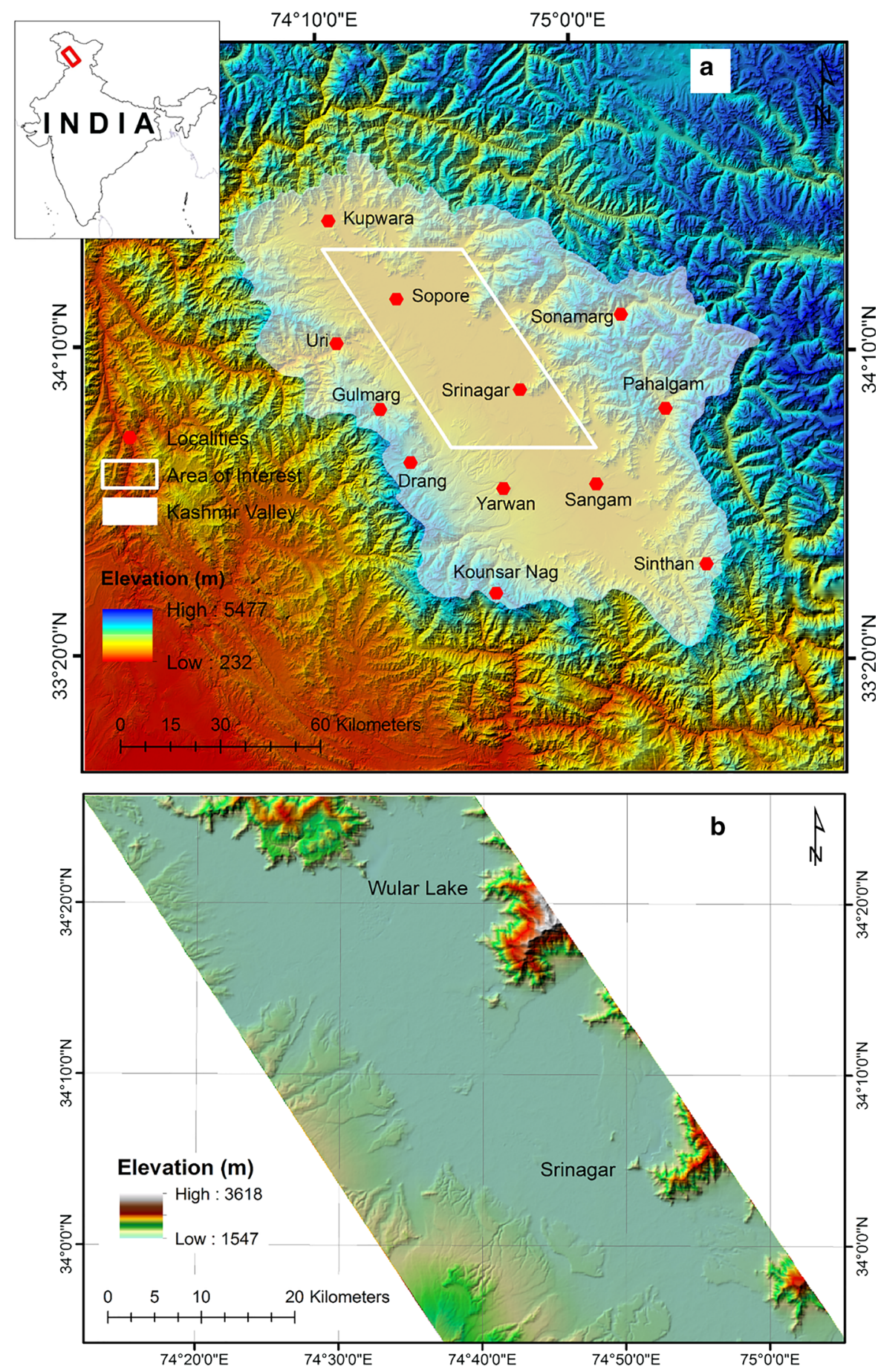

elevations ranging from $\sim 1547$ to $3618 \mathrm{~m}$ above mean sea level in the UTM zone $43 \mathrm{~N}$. The selected area includes most of the valley's floodplain; parts of encompassing mountains and scattered upland patches (Plio-Pleistocene deposits), hosting substantial human population and socioeconomic activities of the valley. The extensive human interference with the natural environment and visible landscape modifications has been the motivation behind the selection of this zone for analysis. 


\section{Data and methodology}

Data

For monitoring LULC change, it is necessary to have at least data of two time periods for comparison. Remote sensing approach usually involves the usage of satellite images of two or multiple dates for quantifying the land use and land cover changes in any area. In this study, the selection of the imageries was made in light of their compatible spatial resolution $(30 \mathrm{~m})$. Landsat data archive having images sufficiently consistent with data from the earlier missions allows assessing long-term regional and global LULC change (Irons et al. 2012). We use Landsat (5, 7, 8) Thematic Mapper-TM (1992), Enhanced Thematic Mapper Plus-ETM+ (2001), and Operational Land Imager-OLI (2015) cloud free scenes for analysing LULC change in the selected part of the Kashmir valley. The images were already preprocessed; therefore, no radiometric calibrations and atmospheric corrections were applied. However, all the images were co-registered to sub-pixel accuracy in ERDAS IMAGINE (9.3) for removing geometric incongruity. Other details of the satellite data used in this study are given in Table 1.

Land use and land cover classification

The LULC information can be obtained from the multiband raster imageries through the process of image interpretation and classification (Li et al. 2014). Image classification (supervised or unsupervised) is intended for an automatic categorisation of pixels with a common reflectance range into specific LULC class (Lillesand and Kiefer 1994; Chica-Olmo and AbarcaHernandez 2000; Tarantino et al. 2015). Supervised classification is a user guided approach that involves selection of training sites as reference for the categorization (Campbell 1996; Lillesand and Kiefer 1994; Jensen 2007). There are many methods available that are being used to implement the supervised classification such as, parallelepiped classification, K-nearest neighbour, minimum distance classification, and so on (Zhu et al. 2006). In the present study we adopted commonly used maximum likelihood classifier (Platt and Goetz 2004) for LULC classification using ERDAS IMAGINE (9.3) software. Maximum likelihood algorithm quantitatively evaluates both the variance and covariance of the spectral response patterns and each pixel is assigned to the class for which it has the highest possibility of association (Shalaby and Tateishi 2007). A total of nine LULC classes (Level I) i.e., agriculture, marshes, built-up, barren, forest, plantation, pasture, water, and shrubs (for details see Table 2) were identified in light of scheme proposed Anderson et al. (1976). With the complementary use of satellite navigation system (GPS), post-classification field visits were performed for ground validation of ambiguous spots and further refinement of the LULC classification. Finally, multitemporal (1992, 2001, and 2015) raster layers were generated and their corresponding statistics was compared for estimation of the LULC change.

\section{Accuracy assessment}

Land use and cover classification is subject to incur some errors; hence the output (maps) needs to be put to test for assessing accuracy using a reliable statistical technique. For that reason, LULC maps are usually accompanied by an accuracy assessment index that includes a clear description of the sampling design (including sample size and, if relevant, details of stratification), an error matrix, the area or proportion of area of each category according to the map, and descriptive accuracy measures such as user's, producer's and overall accuracy (Olofsson et al. 2013). The term 'accuracy' is typically used to express the measure of 'correctness' of a derived map (classification) which is assessed through the construction of error-matrix (Foody 2002). With the development of

Table 1 Characteristics of the satellite data used in the present study

\begin{tabular}{lllccrr}
\hline Landsat & Sensor & Resolution $(\mathrm{m})$ & Range $(\mu \mathrm{m})$ & Bands & Path/row & Acquisition \\
\hline 5 & TM & 30 & $0.45-0.90$ & $1,2,3,4$ & $148-49 / 36-37$ & $15 / 10 / 1992$ \\
7 & ETM+ & 30 & $0.45-0.90$ & $1,2,3,4$ & $148-49 / 36-37$ & $30 / 09 / 2001$ \\
8 & OLI & 30 & $0.452-0.879$ & $2,3,4,5$ & $148-49 / 36-37$ & $24 / 08 / 2015$ \\
\hline
\end{tabular}


Table 2 Land use and land cover classification scheme

\begin{tabular}{|c|c|}
\hline Class & Description \\
\hline Agriculture & $\begin{array}{l}\text { Land devoted to the cultivation of rabi and kharif crops, mainly rice, mustard; maize, and vegetables is included in this } \\
\text { class }\end{array}$ \\
\hline Marshes & $\begin{array}{l}\text { Wetlands, sag ponds, seasonal and permanent aquatic vegetation, and other naturally saturated areas form part of this } \\
\text { category }\end{array}$ \\
\hline Built-up & This class represents the residential areas, commercial establishments, industrial zones, roads and other paved surfaces \\
\hline Barren & The class includes bare lands, rock-strewn, and other soil surfaces that remain devoid of vegetation throughout the year \\
\hline Forrest & $\begin{array}{l}\text { This class corresponds to coniferous vegetation spread over encompassing mountains mainly between the elevations } \\
\text { ranging from } 2500-3600\end{array}$ \\
\hline Plantation & $\begin{array}{l}\text { This category is dominated by the apple, pear, walnut, almond, and cherry orchards and social forestry such as poplar, } \\
\text { willow, and other deciduous trees }\end{array}$ \\
\hline Pasture & The class includes high altitude mountainous rangelands and state owned grass lands used mostly for livestock rearing \\
\hline Water & Open water bodies such as lakes, rivers, and permanent ponds are included in this category \\
\hline Shrubs & Low height woody plants and other bushy vegetation mainly along the margins of forests are part of this class \\
\hline
\end{tabular}

the error-matrix important accuracy assessment elements, such as overall accuracy, omission error, commission error, and kappa coefficient, can be obtained (Lu and Weng 2007). Cohen's (1960) kappa $(\mathrm{k})$ is a robust and extensively used statistical measure to assess the inter-rater agreement between categorical variables.

In the present study accuracy of all the raster layers (1992, 2001, and 2015) was assessed though the development of an error-matrix. A stratified random sampling design was adopted in the accuracy assessment. The generated maps of the time periods-1992, 2001 and 2015 revealed an overall accuracy of $91.1 \%$, $90 \%, 87.2 \%$ and kappa coefficient of $0.9,0.88$, and 0.87 respectively. In general, accuracy of all the three raster layers is acceptable (Anderson et al. 1976); therefore, the results obtained can be considered as reliable to a larger extent. The overall accuracy and kappa coefficient was determined using the Eqs. (1) and (2) (for details see Table 3).

Overall accuracy $=\frac{\sum_{i=1}^{r} x_{i i}}{x}$

where $x_{\mathrm{ii}}$ is the diagonal elements in the error matrix, $x$ is the total number of samples in error matrix

Kappa coefficient $(\hat{K})=\frac{n \sum_{i=1}^{r} x_{i i}-\sum_{i=1}^{r} x_{i+} x_{+i}}{n^{2}-\sum_{i=1}^{r} x_{i+} x_{+i}}$ where $r$ is the number rows in the matrix, $x_{i i}$ is the number of observations in row $i$ and column $i, x_{i+}$ and $x_{+i}$ are marginal totals for row $i$ and column $i$ respectively and $n$ is the total number of observations (pixels).

\section{Results and discussion}

In general Kashmir valley witnessed considerable changes in land use and land cover during last three decades across its length and breadth; however, the changes have been extensive within the selected lowlying central part of the valley that also hosts the primate city (Srinagar), few towns, and a huge number of the villages. The details of land use and land cover changes within the study area during the selected time period (1992-2001-2015) are illustrated in Figs. 2, 3a, b, 4, and 5; and Table 4.

\section{Agriculture}

Agriculture is largest of all the identified classes in the study area. The agriculture land revealed a continuous decline throughout the study period (Fig. 4). The total area under this category has been $55.77 \%, 46.36 \%$ and $39.68 \%$ of the total area in 1992, 2001 and 2015 respectively (Fig. 5). There has been decrease of $16.86 \%$ from 1992 to $2001,14.4 \%$ from 2001 to 2015 and a collective reduction of $28.9 \%$ from 1992 to 2015 
Table 3 Accuracy of LULC maps obtained from satellite data for the selected time periods

\begin{tabular}{lllllllllllll}
\hline CLASS & A & M & BU & B & F & PL & P & W & S & RT & UA (\%) \\
\hline
\end{tabular}

Landsat-OLI 2015

(a)

\begin{tabular}{|c|c|c|c|c|c|c|c|c|c|c|c|}
\hline A & 80 & 10 & 10 & 0 & 0 & 0 & 0 & 0 & 0 & 100 & 80 \\
\hline M & 30 & 70 & 0 & 0 & 0 & 0 & 0 & 0 & 0 & 100 & 70 \\
\hline $\mathrm{BU}$ & 0 & 0 & 100 & 0 & 0 & 0 & 0 & 0 & 0 & 100 & 100 \\
\hline B & 0 & 0 & 0 & 95 & 0 & 0 & 0 & 0 & 5 & 100 & 95 \\
\hline F & 0 & 0 & 0 & 0 & 100 & 0 & 0 & 0 & 0 & 100 & 100 \\
\hline $\mathrm{H}$ & 0 & 0 & 10 & 0 & 10 & 80 & 0 & 0 & 0 & 100 & 80 \\
\hline $\mathrm{P}$ & 0 & 0 & 0 & 0 & 0 & 0 & 100 & 0 & 0 & 100 & 80 \\
\hline W & 0 & 0 & 0 & 0 & 0 & 0 & 0 & 100 & 0 & 100 & 100 \\
\hline S & 0 & 0 & 0 & 0 & 0 & 0 & 5 & 0 & 95 & 100 & 95 \\
\hline $\mathrm{CT}$ & 110 & 80 & 120 & 95 & 110 & 80 & 105 & 100 & 100 & 900 & \\
\hline PA $(\%)$ & 73 & 87 & 83 & 100 & 90 & 100 & 95 & 100 & 95 & & \\
\hline
\end{tabular}

Landsat-ETM + 2001

(b)

\begin{tabular}{|c|c|c|c|c|c|c|c|c|c|c|c|}
\hline A & 80 & 10 & 10 & 0 & 0 & 0 & 0 & 0 & 0 & 100 & 80 \\
\hline M & 30 & 70 & 0 & 0 & 0 & 0 & 0 & 0 & 0 & 100 & 70 \\
\hline BU & 0 & 0 & 100 & 0 & 0 & 0 & 0 & 0 & 0 & 100 & 100 \\
\hline B & 0 & 0 & 0 & 90 & 0 & 0 & 0 & 0 & 10 & 100 & 90 \\
\hline $\mathrm{F}$ & 0 & 0 & 0 & 0 & 100 & 0 & 0 & 0 & 0 & 100 & 100 \\
\hline $\mathrm{H}$ & 10 & 0 & 10 & 0 & 0 & 80 & 0 & 0 & 0 & 100 & 80 \\
\hline $\mathrm{P}$ & 0 & 0 & 0 & 0 & 0 & 0 & 100 & 0 & 0 & 100 & 100 \\
\hline W & 0 & 0 & 0 & 0 & 0 & 0 & 0 & 100 & 0 & 100 & 100 \\
\hline S & 0 & 0 & 0 & 0 & 0 & 0 & 10 & 0 & 90 & 100 & 90 \\
\hline CT & 120 & 80 & 120 & 90 & 100 & 80 & 110 & 100 & 100 & 900 & \\
\hline PA (\%) & 67 & 88 & 83 & 100 & 100 & 100 & 90 & 100 & 90 & & \\
\hline
\end{tabular}

Landsat-TM 1992

(c)

\begin{tabular}{lrrrrrrrrrrr} 
A & 100 & 0 & 0 & 0 & 0 & 0 & 0 & 0 & 0 & 100 & 100 \\
M & 0 & 90 & 0 & 0 & 0 & 10 & 0 & 0 & 0 & 100 & 82 \\
BU & 0 & 0 & 100 & 0 & 0 & 0 & 0 & 0 & 0 & 100 & 100 \\
B & 0 & 0 & 0 & 80 & 0 & 10 & 0 & 0 & 10 & 100 & 87 \\
F & 0 & 0 & 0 & 0 & 80 & 0 & 10 & 0 & 10 & 100 & 75 \\
H & 10 & 0 & 10 & 0 & 0 & 80 & 0 & 0 & 0 & 100 & 80 \\
P & 0 & 0 & 0 & 10 & 0 & 0 & 80 & 0 & 10 & 100 & 75 \\
W & 0 & 10 & 0 & 0 & 0 & 0 & 0 & 90 & 0 & 100 & 86 \\
S & 0 & 0 & 0 & 0 & 0 & 0 & 0 & 0 & 100 & 100 & 100 \\
CT & 110 & 100 & 110 & 90 & 80 & 100 & 90 & 90 & 130 & 900 \\
PA (\%) & 90 & 90 & 90 & 89 & 100 & 80 & 89 & 100 & 77 & \\
\hline
\end{tabular}

Diagonal Italic numbers represent correctly classified samples for each LULC class

A: agriculture, M: marshes, BU: built-up, B: barren, F: forest, PL: plantation, P: pasture, W: water, S: Shrubs, RT: row total, CT: column total, UA: user's accuracy, PA: producer's accuracy

${ }^{(a)}$ Sumof diagonal $=820$; Total $=900$; Overall accuracy $=91.1 \%$; Kappa coefficient $(\mathrm{K})=0.9$

${ }^{\text {(b) }}$ Sum of diagonal $=810$; Total $=900$; Overall accuracy $=90 \%$; Kappa coefficient $(\mathrm{K})=0.88$

${ }^{(\mathrm{c})}$ Sum of diagonal $=800 ;$ Total $=900 ;$ Overall accuracy $=87.2 \%$; Kappa coefficient $(\mathrm{K})=0.87$ 

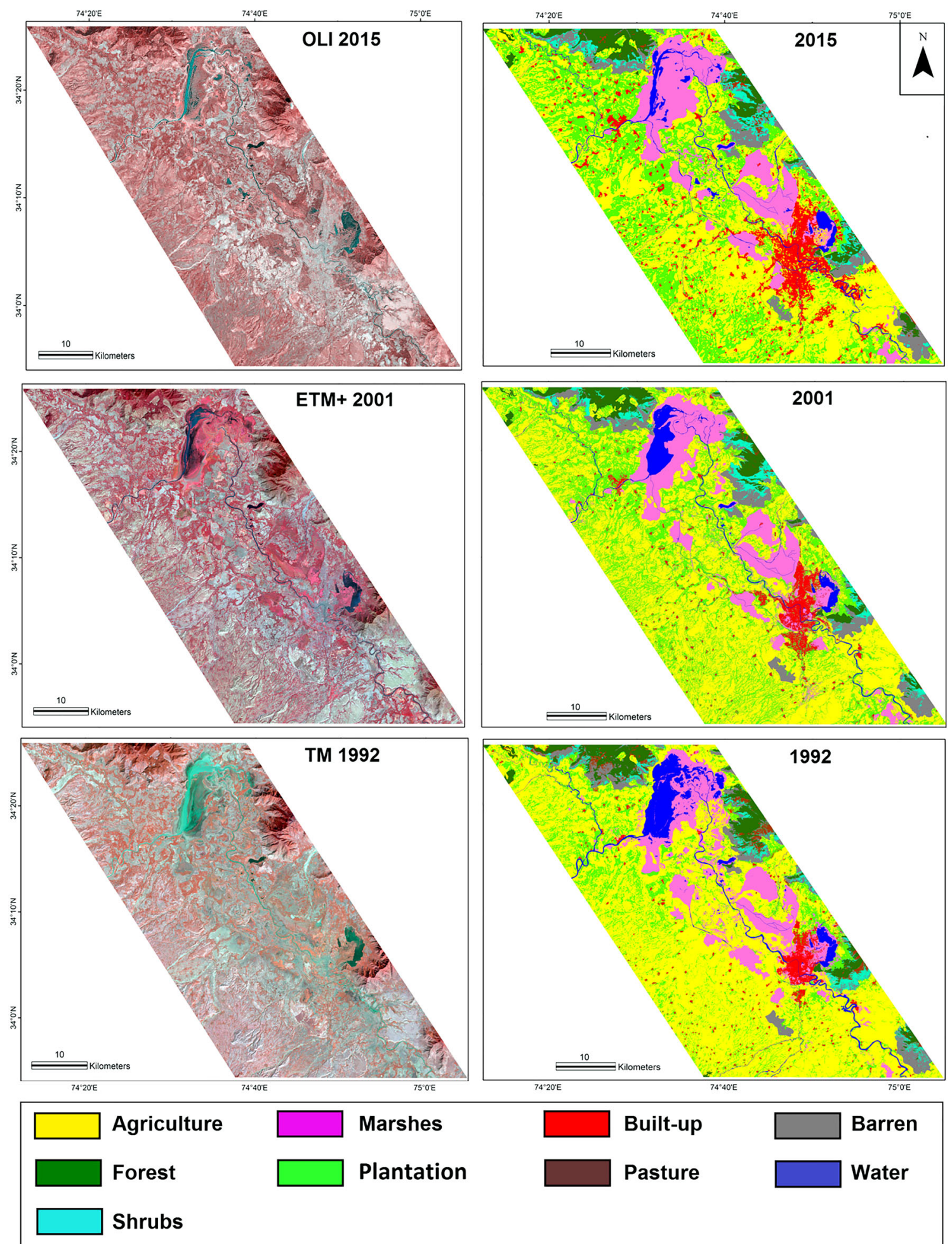

Fig. 2 Satellite images: Landsat: OLI, ETM +, TM (left) and corresponding classified land use and land cover maps (right) 
Table 4 Land use and land cover change statistics (in hectares)

\begin{tabular}{lrrrrrr}
\hline Class & \multicolumn{1}{c}{1992} & \multicolumn{1}{c}{ 2001 } & \multicolumn{1}{c}{2015} & Change 1992-2001 & Change 2001-2015 & Net change 1992-2015 \\
\hline Agriculture & $133,825.90$ & $111,256.48$ & $95,211.27$ & $-22,569.42$ & $-16,045.21$ & $-38,614.63$ \\
Marshes & $27,027.86$ & $28,147.22$ & $29,258.46$ & 1119.36 & 1111.24 & 2230.60 \\
Built-up & 5570.98 & 7566.27 & $16,627.14$ & 1995.29 & 9060.87 & $11,056.16$ \\
Barren & 9162.10 & $11,584.07$ & $11,801.52$ & 2421.97 & 217.45 & 2639.42 \\
Forest & $10,498.90$ & 8727.30 & 9785.52 & -1771.60 & 1058.22 & -713.38 \\
Plantation & $34,491.30$ & $59,978.16$ & $64,837.17$ & $25,486.86$ & 4859.01 & $30,345.87$ \\
Pasture & 2929.54 & 414.73 & 821.79 & -2514.81 & 407.06 & -2107.75 \\
Water & $11,755.61$ & 7020.36 & 6014.97 & -4735.26 & -1005.39 & -5740.64 \\
Shrubs & 4688.23 & 5250.95 & 5572.8 & 562.73 & 321.85 & 884.57 \\
\hline
\end{tabular}

in agriculture land. This is mainly because the period from 1992 to 2015 witnessed tremendous shift in land use practice from paddy to apple cultivation in the Kashmir valley. Moreover, a considerable proportion of agriculture land was lost to built-up expansion during this period. The statistics is in agreement with the trend observed by the previous studies conducted in various parts of Kashmir valley (e.g., Joshi et al. 2002; Alam et al. 2011; Shah 2012; Nanda et al. 2014; Kuchay et al. 2016).

\section{Marshes}

Marshy land represents transitional areas sharing properties both with purely aquatic (water) and purely terrestrial (land) systems, concentric mostly to lowlying part of the study area (Fig. 2). This LULC category revealed a positive growth constituting $11.26 \%, 11.73 \%$ and $12.19 \%$ in 1992, 2001, and 2015 respectively (Figs. 4 and 5). This change is not good transformation as it seems because the area under marshy class increases at the cost of open water bodies (lakes). All the major lakes of the valley have attained eutrophication condition owing to excessive supply of nutrients and sediment load from river catchments (Ganai et al. 2010); thus generally losing their area to this (marshes) LULC category.

\section{Built-up}

Few LULC changes are comparatively more noticeable in Kashmir; tremendous increase in built-up area is one of them (Figs. 2 and 3a). Comprising mainly of residential and commercial establishments, the total area under built-up has been $2.32 \%, 3.15 \%$ and 6.92 in
1992, 2001, and 2015 respectively, registering a total growth of $198.45 \%$ from 1992 to 2015 (Figs. 4 and 5). The built-up expansion has been mostly encroaching the agriculture land and wetlands (e.g., Kumar 2016). Particularly expanding along roads and peripheral zones, the increasing built-up adversely affects the environmental quality of the region (e.g., Kuchay and Bhat 2014). This pattern is also consistent with the national (India) status as well, where 0.7 million hectares of agriculture land were lost to urban expansion during 2001-2010 (http://lcluc.umd.edu/ newsletter_article_Karen_format.php).

Barren

The barren LULC category is among the small LULC categories of this classification contributing an area of $3.81 \%, 4.82 \%$, and $4.91 \%$ in 1992,2001 , and 2015 correspondingly (Figs. 4 and 5). Experiencing positive changes, the growth of this class is attributed to deforestation especially along piedmonts and increase in industrial and construction project sites such as brick kilns, highways, and quarries.

Forests

Forest were observed to be revealing two change patterns during the selected time period i.e., the area under forest category revealed reduction i.e., $4.37-3.63 \%$ from 1992 to 2001, and an increase to $4.07 \%$ of the total area from 2001 to 2015 (Fig. 2, 3a, 4 , and 5). The decade of 1990 s witnessed a widespread illegal logging and loss of forests owing to political instability in the Kashmir valley. Large forest stands were completely wiped out especially in the higher 

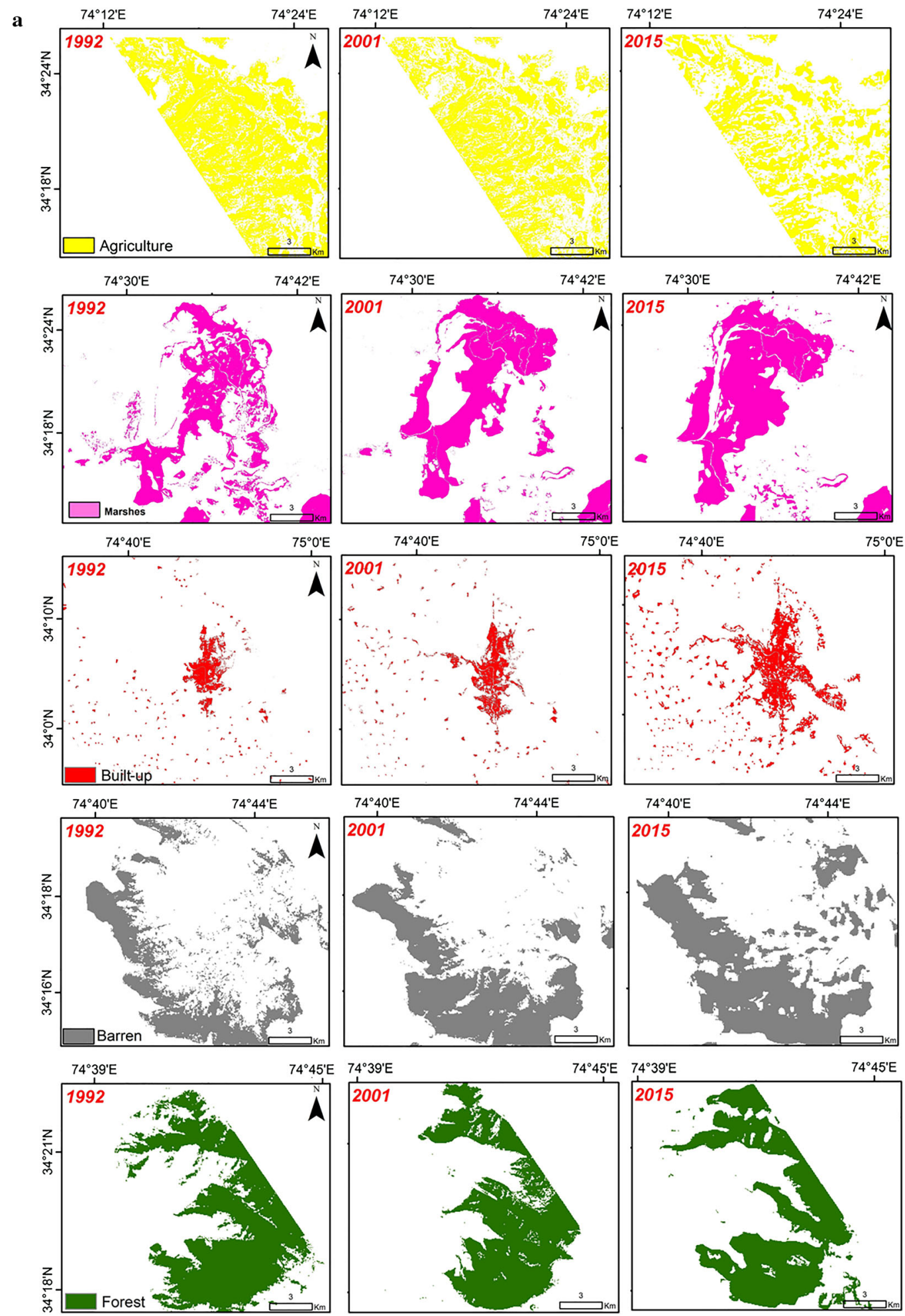

Fig. 3 a, b Land and land cover changes at different locations in the study area (1992-2011-2015) 
b
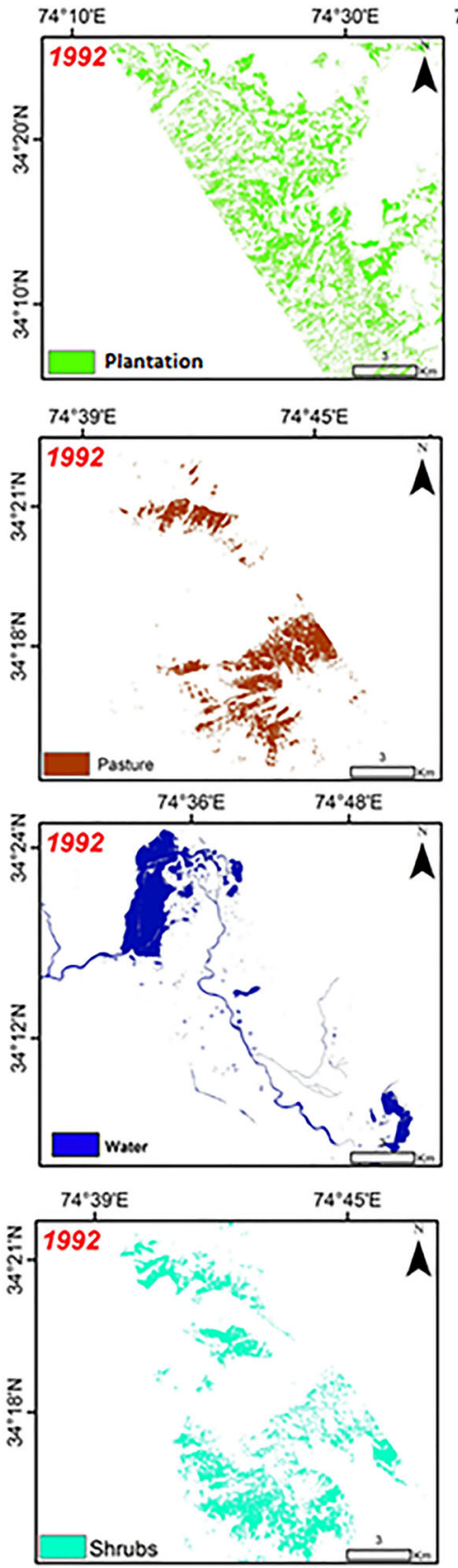
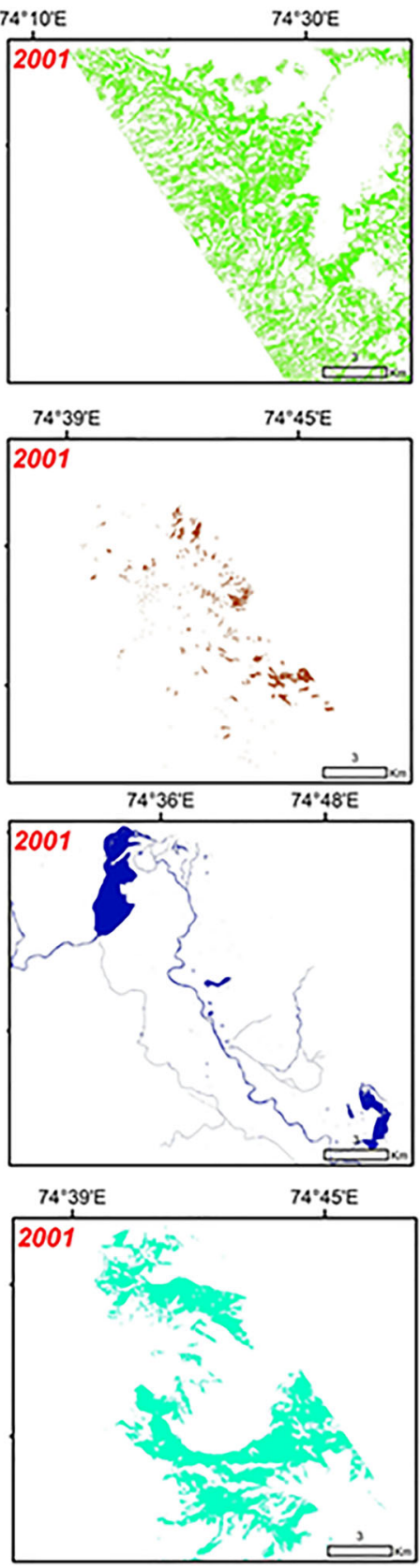
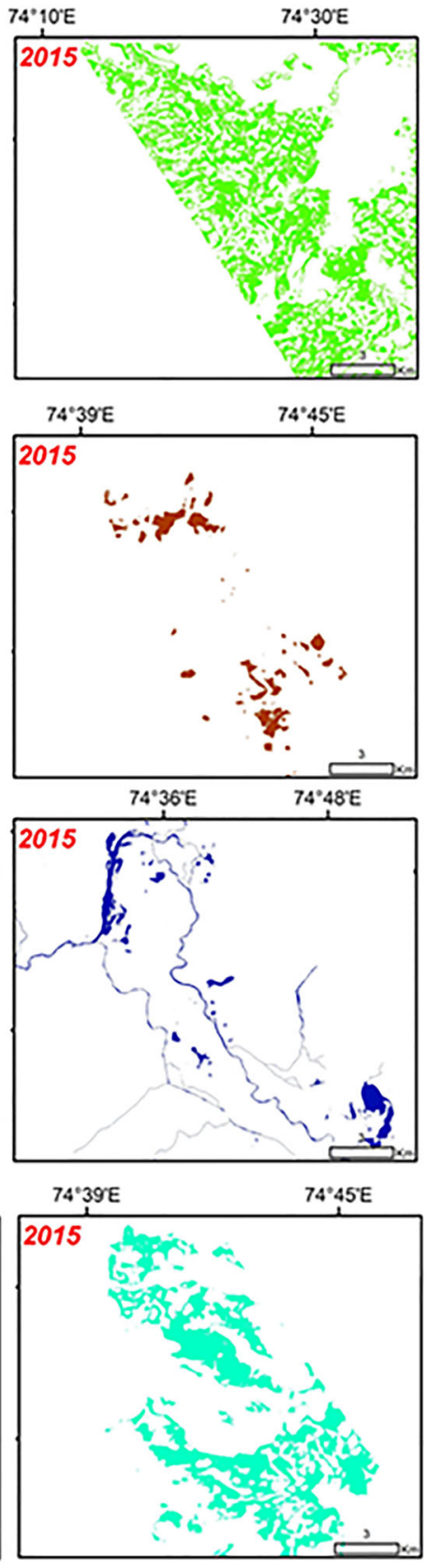

Fig. 3 continued

reaches of the valley (http://www.kashmirlife.net/ straining-forests-issue-31-vol-07-87503/). However; with serious efforts from different sections of society and law enforcing agencies the timber smuggling was curbed to a larger level; and that resulted in a pattern of forest land changes, as observed in the present study.
Plantation

Plantation especially in form of horticulture (e.g., apple orchards) and social forestry (e.g., poplar and willow trees) is a LULC class that has grown fast and extensively across the Kashmir valley (Figs. 2, 3b, 4, and 5). Horticulture contributing 7-8\% to Gross State 
Fig. 4 Area under different land use and land cover classes $(1992,2001$, and 2015)

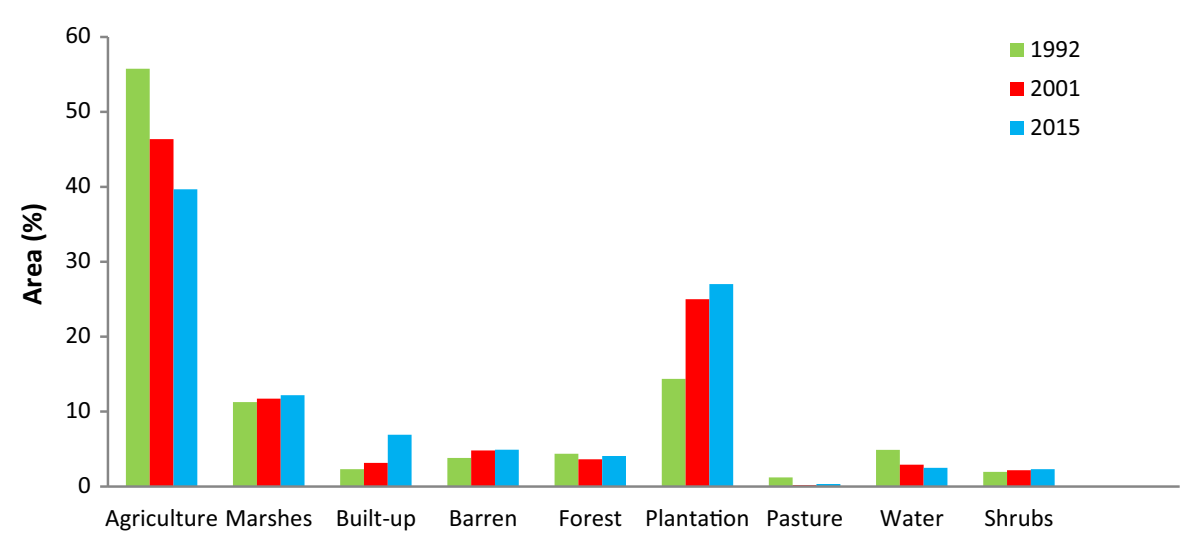

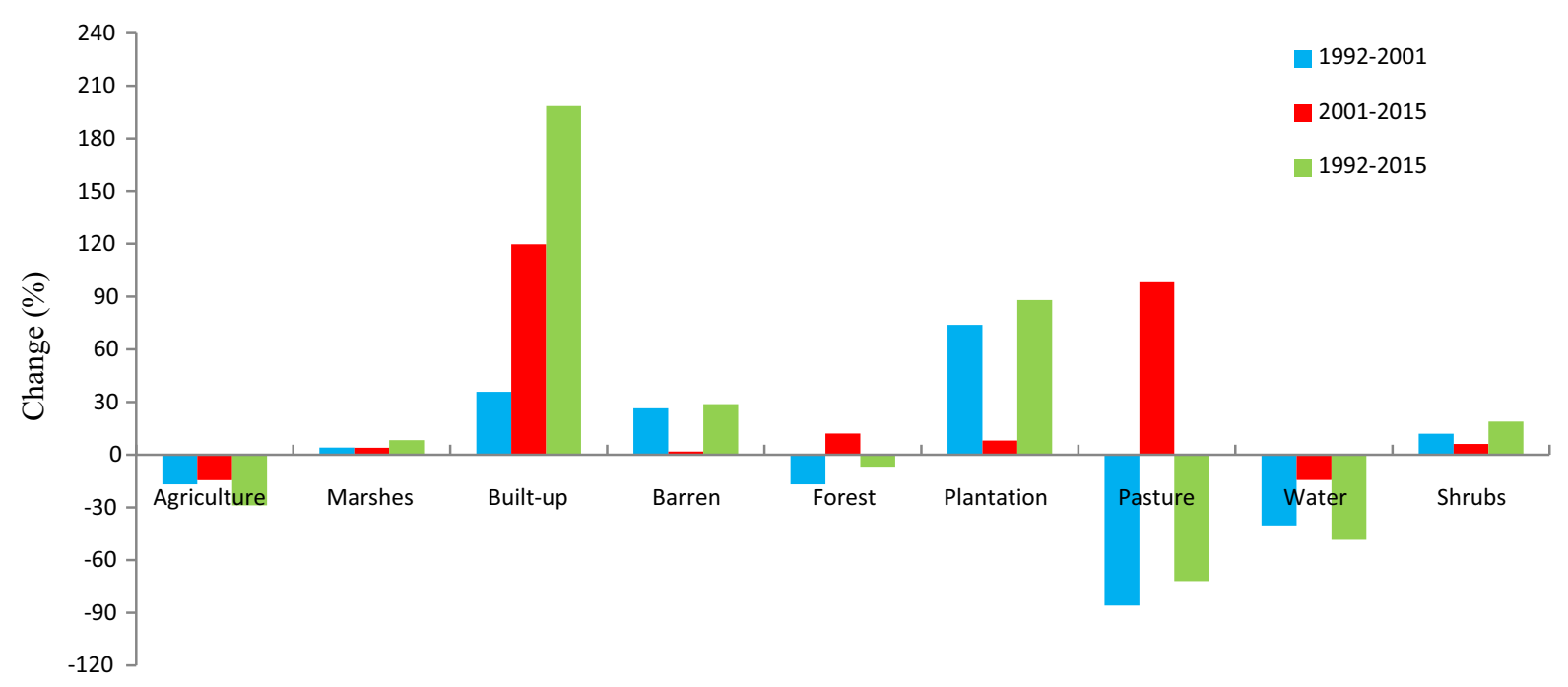

Fig. 5 Changes within each land use and land cover class (1992-2001-2015)

Domestic Product (GSDP) (http://hortikashmir.gov. in/) has been primary economic activity of approximately $60 \%$ of people in the valley. Experiencing an increasing trend, the area under horticulture land has changed from $14.37 \%, 24.99 \%$, and $27.02 \%$ during 1992, 2001, and 2015 respectively; however, major change has been observed to have taken place from 1992 to 2001 only (Fig. 5). The plantation gained most of its area from paddy fields; the conversion of agriculture land to horticulture has been mainly because of higher economic returns produced by the later, especially from the apple production.

\section{Pasture}

Pasture represents one of the smaller classes of this classification. The area under the pasture also revealed two change patterns i.e. decrease from 1.22 to $0.17 \%$ during 1992-2001 and increase to $0.34 \%$ of the total area in 2015 (Figs. 2, 3b, 4, and 5).

\section{Water}

The area under open water has reduced to almost half (Fig. 2). There has been decline in the total share of this LULC class from $4.89 \%, 2.92 \%$, and $2.5 \%$ during 1992, 2001, and 2015 respectively; however, the rate of reduction has been maximum from 1992 to 2001 (Figs. 3b, 4, and 5). Owing to changing climate and anthropogenic effects the water bodies are most stressed natural resource in the Kashmir valley. The lakes and rivers in the valley reveal significant morphological changes and loss of the area owing to huge human intervention and fluctuations in water 
budget. Sediment load received from the feeding rivers has been another important factor contributing to dwindling bathymetric properties of water bodies in the study area (e.g., Rashid and Naseem 2008; Alam et al. 2011). Moreover, poor management practices have resulted in pollution and degraded quality of theses valuable aquatic ecosystems.

Shrubs

The total area under shrubs constituted 1.95\%, 2.18\%, and $2.32 \%$ in 1992, 2001, and 2015 respectively revealing an increasing trend (Figs. 2, 3b, 4, and 5). In this classification shrubs are mostly representing intermediate zones between forested and non-forested areas gaining their area mainly from forests and agriculture land.

Without any operational land use policy and poor resource management practices, the LULC changes have been mostly haphazard in the study area, having long lasting adverse effects from the outlook of environmental management and planning. For example, the adversity of the land transformation is more apparent in aquatic ecosystems (lakes, rivers, wetlands) of the valley; that experienced bathymetric changes (siltation), loss in areal extent, nutrient influx, invasion of alien species and pollution.

Similarly, horticulture intensification through the use of pesticides and chemical fertilizers for cultivation of profitable and more productive crop varieties (e.g., apple) has led to air and water pollutions in the valley. The toxicity of air and water owing to the use of pesticides and chemical fertilizers has resulted in complete extinction of many animal and plant species, including serious effects on health of the resident population.

Moreover, the continued decline of agriculture land may have serious impact on self-sufficiency and food security scenario of the Kashmir valley. Likewise, uncontrolled housing expansion has resulted in exposure of the communities to various natural hazards (e.g., Alam et al. 2018; Bhat et al. 2018, 2019a, b). The tremendous unplanned settlement expansion in some areas poses a serious threat from flood (low-lying flood prone) and seismic hazards (areas with soils having high liquefaction potential).

Population growth, urbanization, tourism, market forces and other development activities are principal drivers of LULC change in the Kashmir valley. Other factors such as economic returns from the cash crops and climate change have also played a role in shifting land from one use to another. Moreover, awareness regarding the importance of environmental health among the people and their perception regarding various economic activities for their livelihood has also been a critical element of the LULC change in the valley.

\section{Conclusion}

Land use and land cover can be considered as an upper most layer of the earth that changes both by natural and anthropogenic actors. The changes are effectively captured by the remote sensing satellite sensors with different spectral, spatial, and temporal resolutions. The archived images provide an opportunity to assess the LULC changes in a given area on desired time intervals. This study demonstrates the pattern of land use and land cover change between 1992 and 2001, and 2015 in the central part of the Kashmir valley using Landsat satellite data. The identified LULC classes revealed substantial change patterns; for example, the area under agriculture, forest, pasture, and water revealed a declining trend from 1992 to 2015 , with a net change of $-38,614.63,-713.38$, -2107.75 , and -5740.64 ha respectively. Whereas, the LULC categories such as marshes, built-up, barren, plantation, and shrubs exhibited general increasing trend; the net positive change observed in each class from 1992 to 2015 has been 2230.60, $11,056.16,2639.42,30,345.87$, and 884.57 ha correspondingly. Most of these LULC changes are unplanned and predominantly a result of anthropogenic activities, with a range of negative impacts on the environment. We assume the results of this study would provide an input to policy makers in understanding the scenario of land use and land cover changes and formulating an effective and eco-friendly land use policy in the Kashmir valley.

Acknowledgements We acknowledge the US National Aeronautics and Space Administration (NASA) for making available huge archive of satellite data from the Landsat mission. We are also indebted to the editor GeoJournal and anonymous reviewers for their constructive review that helped to improve the structure and quality of this paper. 
Open Access This article is distributed under the terms of the Creative Commons Attribution 4.0 International License (http:// creativecommons.org/licenses/by/4.0/), which permits unrestricted use, distribution, and reproduction in any medium, provided you give appropriate credit to the original author(s) and the source, provide a link to the Creative Commons license, and indicate if changes were made.

\section{References}

Ahmad, S., Alam, A., Ahmad, B., Bhat, M. I., \& Bhat, M. S. (2015). Geomorphic evidence of unrecognized Balapur fault segment in the southwest Kashmir basin of northwest Himalayas. Geomorphology. https://doi.org/10.1016/j. geomorph.2015.09.006.

Alam, A., Ahmad, S., Bhat, M. S., \& Ahmad, B. (2015a). Tectonic evolution of Kashmir basin in northwest Himalayas. Geomorphology, 239, 114-126. https://doi.org/10. 1016/j.geomorph.2015.03.025.

Alam, A., Ahmad, S., Bhat, M. S., \& Ahmad, B. (2015b). Response to the comment by Shah, A. A. (2015) and further evidence supporting the dextral strike-slip pull-apart evolution of the Kashmir basin along the central Kashmir fault (CKF). Geomorphology. https://doi.org/10.1016/j. geomorph.2015.06.017.

Alam, A., Bhat, M. S., Hakeem, F., Ahmad, B., Ahmad, S., \& Sheikh, A. H. (2018). Flood risk assessment of Srinagar city in Jammu and Kashmir, India. International Journal of Disaster Resilience in the Built Environment, 9(2), 114-129. https://doi.org/10.1108/IJDRBE-02-2017-0012.

Alam, A., Bhat, M. S., Kotlia, B. S., Ahmad, B., Ahmad, S., Taloor, A. K., et al. (2017). Coexistent pre-existing extensional and subsequent compressional tectonic deformation in the Kashmir basin, NW Himalaya. Quaternary Internation, 444(Part A), 201-208. https://doi.org/10. 1016/j.quaint.2017.06.009.

Alam, A., Rashid, S. M., Bhat, M. S., \& Sheikh, A. H. (2011). Impact of land use/land cover dynamics on Himalayan wetland ecosystem. Journal of Experimental Sciences, 2(3), 60-64.

Anderson, J. R., Hardy, E. E., Roach, J. T., \& Witmer, R. E. (1976). A land-use and land-cover classification system for use with remote sensor data. US Geological Survey Professional Paper 964, Washington, DC.

Barnsley, M. J., \& Barr, S. L. (1996). Inferring urban land use from satellite sensor images using kernel based spatial reclassification. Photogramm Eng Remote Sensing, 62(8), 949-958.

Bhat, M. S., Ahmad, B., Alam, A., Farooq, H., \& Ahmad, S. (2019a). Flood hazard assessment of the Kashmir valley using historical hydrology. Journal of Flood Risk Management. https://doi.org/10.1111/jfr3.12521.

Bhat, M. S., Alam, A., Ahmad, B., Kotlia, B. S., Farooq, H., Taloor, A. K., et al. (2018). Flood frequency analysis of river Jhelum in Kashmir. Quaternary International. https:// doi.org/10.1016/j.quaint.2018.09.039.

Bhat, M. S., Alam, A., \& Ahmad, S. (2019b). Flood hazard assessment of upper Jhelum basin using morphometric parameters. Environmental Earth Sciences. https://doi.org/ 10.1007/s12665-019-8046-1.

Brown, D. G., Pijanowski, B. C., \& Duh, J. D. (2000). Modeling the relationships between land use and land cover on private lands in the Upper Midwest, USA. Journal of Environmental Management, 59(4), 247-263. https://doi.org/ 10.1006/jema.2000.0369.

Burley, T. M. (1961). Land use or land utilization? Professional Geographer, 14(5), 18-20.

Campbell, J. B. (1996). Introduction to remote sensing (2nd ed.). London: Taylor and Francis.

Chica-Olmo, M., \& Abarca-Hernandez, F. (2000). Computing geostatistical image texture for remotely sensed data classification. Computers \& Geosciences, 26(4), 373-383.

Cohen, Jacob. (1960). A coefficient of agreement for nominal scales. Educational and Psychological Measurement, 20(1), 37-46.

David, K., Yetta, G., Agung, F., Sharon, H., \& Alison, C. (2016). Land use planning for disaster risk reduction and climate change adaptation: Operationalizing policy and legislation at local levels. International Journal of Disaster Resilience in the Built Environment, 7(2), 158-172.

Diallo, Y., Hu, G., \& Wen, X. (2009). Applications of remote sensing in land use/land cover change detection in Puer and Simao Counties, Yunnan Province. Journal of American Science, 5(4), 157-166.

Erener, A., Düzgün, S., \& Yalciner, A. C. (2012). Evaluating land use/cover change with temporal satellite data and information systems. Procedia Technology, 1, 385-389. https://doi.org/10.1016/j.protcy.2012.02.079.

Foley, J. A., et al. (2005). Global consequences of land use. Science, 309(5734), 570. https://doi.org/10.1126/science. 1111772.

Foody, G. M. (2002). Status of land cover classification accuracy assessment. Remote Sensing of Environment, 80(1), 185-201.

Ganai, A. H., Parveen, S., Khan, A. A., \& Maryam, H. (2010). Phytoplankton diversity at Watlab Ghat in Wular Lake, Kashmir. Journal of Ecology and the Natural Environment, 2(8), 140-146.

Gao, Y., \& Zhang, W. (2009). LULC classification and topographic correction of Landsat-7 ETM + imagery in the Yangjia River Watershed: The influence of DEM resolution. Sensors, 9(3), 1980-1995. https://doi.org/10.3390/ s90301980.

Güler, M., Yomralıoglu, T., \& Reis, S. (2007). Using landsat data to determine land use/land cover changes in Samsun, Turkey. Environmental Monitoring and Assessment, 127(1-3), 155-167. https://doi.org/10.1007/s10661-0069270-1.

Gumma, M. K., Thenkabail, P. S., Hideto, F., Nelson, A., Dheeravath, V., Busia, D., et al. (2011). Mapping irrigated areas of Ghana using fusion of $30 \mathrm{~m}$ and $250 \mathrm{~m}$ resolution remote-sensing data. Remote Sensing, 3(4), 816-835.

Hegazy, I. R., \& Kaloop, M. R. (2015). Monitoring urban growth and land use change detection with GIS and remote sensing techniques in Daqahlia governorate Egypt. International Journal of Sustainable Built Environment, 4(1), 117-124.

Helmer, E. H., Brown, S., \& Cohen, W. B. (2000). Mapping montane tropical forest successional stage and land use 
with multi-date Landsat imagery. International Journal of Remote Sensing, 21(11), 2163-2183. https://doi.org/10. 1080/01431160050029495.

Herold, M., Scepan, J., \& Clarke, K. C. (2002). The use of remote sensing and landscape-metrics to describe structures and changes in urban land uses. Environment and Planning A, 34(8), 1443-1458.

Irons, J. R., Dwyer, J. L., \& Barsi, J. A. (2012). The next Landsat satellite: The landsat data continuity mission. Remote Sensing of Environment, 122, 11-21.

Jensen, J. R. (2007). Remote sensing of the environment (2nd ed.). Upper Saddle River: Pearson Prentice Hall.

Ji, W., Ma, J., Twibell, R. W., \& Underhill, K. (2005). Characterizing urban sprawl using multi-stage remote sensing images and landscape metrics. Computers, Environment and Urban Systems, 30(2006), 861-879.

Jia, K., Wei, X., Gu, X., Yao, Y., Xie, X., \& Li, B. (2014). Land cover classification using Landsat 8 Operational Land Imager data in Beijing, China. Geocarto International, 29(8), 941-951. https://doi.org/10.1080/10106049.2014. 894586.

Joshi, P. K., Rashid, H., \& Roy, P. S. (2002). Landscape dynamics in Hokersar Wetland, Jammu \& Kashmir-An application of geospatial approach. Journal of the Indian Society of Remote Sensing, 30(1-2), 1-5.

Kuchay, N. A., \& Bhat, M. S. (2014). Analysis and Simulation of urban expansion of Srinagar City. Transactions of the Institute of Indian Geographers, 36(1), 121.

Kuchay, N. A., Bhat, M. S., \& Shafi, N. (2016). Population growth, urban expansion and housing scenario in Srinagar City, J\&K, India. Journal of Geography and Regional Planning, 9(1), 1-11. https://doi.org/10.5897/JGRP2015. 0506.

Kumar, R. (2016). Flood hazard assessment of 2014 floods in Sonawari sub-district of Bandipore district (Jammu \& Kashmir): An application of geoinformatics. Remote Sensing Applications: Society and Environment, 4, 188-203.

Kumar, R., \& Acharya, P. (2016). Flood hazard and risk assessment of 2014 floods in Kashmir valley: A spacebased multisensor approach. Natural Hazards, 84(1), 437-464. https://doi.org/10.1007/s11069-016-2428-4.

Lambin, E. F. (1997). Modelling and monitoring land-cover change processes in tropical regions. Progress in Physical Geography, 21(3), 375-393.

Lambin, E. F., Turner, B. L., Geist, H. J., Agbola, S. B., Angelsen, A., Bruce, J. W., et al. (2001). The causes of land-use and land-cover change: Moving beyond the myths. Global Environmental Change, 11(2), 261-269.

Li, M., Zang, S., Zhang, B., Li, S., \& Wu, C. (2014). A review of remote sensing image classification techniques: The role of spatio-contextual information. European Journal of Remote Sensing, 47(1), 389-411. https://doi.org/10.5721/ EuJRS20144723.

Lillesand, T. M., \& Kiefer, R. W. (1994). Remote sensing and image interpretation (4th ed.). New York: Wiley.

Liu, T., \& Yang, X. (2015). Monitoring land changes in an urban area using satellite imagery, GIS and landscape metrics. Applied Geography, 56, 42-54.

Lo, C. P. (1986). Applied remote sensing (p. 227). New York: Longman Inc.
Loveland T. R., \& Acevedo W. (2006) Land cover change in the Eastern United States, US Geological survey. https:// landcovertrends.usgs.gov/east/regionalSummary.html. Accessed 1 Sept 2018.

Lu, D., Hetrick, S., Moran, E., \& Li, G. (2012). Application of time series landsat images to examining land-use/landcover dynamic change. Photogrammetric Engineering and Remote Sensing, 78(7), 747-755.

Lu, D., \& Weng, Q. (2004). Spectral Mixture Analysis of the Urban Landscape in Indianapolis with Landsat ETM + Imagery. Photogrammetric Engineering and Remote Sensing, 70(9), 1053-1062.

Lu, D., \& Weng, Q. (2007). A survey of image classification methods and techniques for improving classification performance. International Journal of Remote Sensing, 28(5), 823-870. https://doi.org/10.1080/01431160600746456.

Nanda, et al. (2014). Changes in land-use/land-cover dynamics using geospatial techniques: A case study of Vishav drainage basin. Journal of Geography and Regional Planning., 7(4), 69-77. https://doi.org/10.5897/JGRP2014.0443.

Nelson, F. (1983). Detecting forest canopy change due to insect activity using Landsat MSS. Photogrammetric Engineering and Remote Sensing, 49(9), 1303-1314.

Ojima, D. S., Galvin, K. A., \& Turner, B. L. (1994). The global impact of land-use change. BioScience, 44(5), 300.

Olofsson, P., FoodyG, M., StehmanS, V., \& WoodcockC, E. (2013). Making better use of accuracy data in land change studies: Estimating accuracy and area and quantifyinguncertainty using stratified estimation. Remote Sensing of Environment, 129, 122-131. https://doi.org/10.1016/j.rse. 2012.10.031.

Platt, R. V., \& Goetz, A. H. (2004). A comparison of AVIRIS and landsat for land use classification at the urban fringe. Photogrammetric Engineering and Remote Sensing, 70(7), 813-819.

Quintas-Soriano, C., Castro, A. J., Castro, H., \& García-Llorente, M. (2016). Impacts of land use change on ecosystem services and implicationsfor human well-being in Spanish drylands. Land Use Policy, 54, 534-548.

Rashid, H., \& Naseem, G. (2008). Quantification of loss in spatial extent of lakes and wetlands in suburbs of Srinagar City during last century using geospatial approach. In Proceedings of Taal 2007: 12th world lake conference (pp. 653-658).

Seto, K. C., \& Kaufmann, R. K. (2005). Using logit models to classify land cover and land-cover change from Landsat Thematic Mapper. International Journal of Remote Sensing, 26(3), 563-577. https://doi.org/10.1080/ 01431160512331299270.

Shah, S. A. (2012). Use of geographic information system in land use studies: A micro level analysis. European Journal of Applied Sciences, 4(3), 123-128. https://doi.org/10. 5829/idosi.ejas.2012.4.3.268.

Shalaby, A., \& Tateishi, R. (2007). Remote sensing and GIS for mapping and monitoring land cover and land-use changes in the Northwestern coastal zone of Egypt. Applied Geography, 27(1), 28-41.

Shaw, R., \& Banba, M. (2017). Land use management in disaster risk reduction: An overview. In M. Banba \& R. Shaw (Eds.), Land use management in disaster risk reduction. 
Disaster risk reduction (methods, approaches and practices). Tokyo: Springer.

Singh, A. (1989). Review article digital change detection techniques using remotely-sensed data. International Journal of Remote Sensing, 10(6), 989-1003. https://doi.org/10. 1080/01431168908903939.

Tarantino, E., Novelli, A., Aquilino, M., Figorito, B., \& Fratino, U. (2015). Comparing the MLC and JavaNNS approaches in classifying multi-temporal LANDSAT satellite imagery over an ephemeral river area. International Journal of Agricultural and Environmental Information Systems, 6(4), 83-102. https://doi.org/10.4018/IJAEIS.2015100105.

Turner, B. L., Moss, R. H., \& Skole, D. L. (1993). Relating land use and global land-cover change. In Unknown host publication title. international geosphere-biosphere programme, Stockholm; Report, 24/human dimensions of global environmental change programme, Barcelona; Report 5.
Yang, X. (2002). Satellite monitoring of urban spatial growth in the Atlanta metropolitan area. Photogrammetric Engineering and Remote Sensing, 68(7), 725-734.

Yang, X., \& Liu, Z. (2005). Using satellite imagery and GIS for land-use and land-cover change mapping in an estuarine watershed. International Journal of Remote Sensing, 26(23), 5275-5296. https://doi.org/10.1080/0143116050 0219224.

Zhu G. B., Liu X. L., \& Jia Z. G. (2006). A multi-resolution hierarchy classification study compared with conservative methods. In ISPRS WG II/3, II/6 Workshop "Multiple representation and interoperability of spatial data". Hanover, Germany, February 22-24, 2006.

Publisher's Note Springer Nature remains neutral with regard to jurisdictional claims in published maps and institutional affiliations. 